Proyecciones Journal of Mathematics

Vol. 38, No 1, pp. 111-127, March 2019.

Universidad Católica del Norte

Antofagasta - Chile

\title{
Asymptotic properties of solutions to third order neutral differential equations with delay
}

\author{
Linda D. Oudjedi \\ University of Oran, Algeria \\ Belaib Lekhmissi \\ University of Oran, Algeria \\ and \\ Moussadek Remili \\ University of Oran, Algeria \\ Received: March 2018. Accepted : June 2018
}

\begin{abstract}
This paper concerns the asymptotic properties of solutions of a class of third-order neutral differential equations with delay. We give sufficient conditions for every solution to be converges to zero, bounded and square integrable. An example is also given to illustrate the results.
\end{abstract}

Keywords : Uniform ultimate boundedness, square integrability, Lyapunov functional, neutral differential equation of third order.

Subjclass [2010] Mathematics Subject Classification : 34D05, $34 D 20,34 K 40$. 


\section{Introduction}

In this article, sufficient conditions are obtained such that every solution of (1.1) tends to zero as $t \rightarrow \infty$ of the neutral equation of the form

$$
(1.1)[x(t)+\beta x(t-r)]^{\prime \prime \prime}+a(t) x^{\prime \prime}(t)+b(t) x^{\prime}(t)+c(t) f(x(t-r))=0,
$$

and the boundedness and the square integrability of

$$
\left(1.2[x(t)+\beta x(t-r)]^{\prime \prime \prime}+a(t) x^{\prime \prime}(t)+b(t) x^{\prime}(t)+c(t) f(x(t-r))=h(t),\right.
$$

where, $\beta$ and $r$ are constants with $0 \leq \beta \leq 1$ and $r \geq 0, h(t)$ and $f(x)$ continuous functions depending only on the arguments shown and $f^{\prime}(x)$ exist and is continuous for all $x$.

By a solution of (1.1) we mean a continuous function $x:\left[t_{x}, \infty\right) \rightarrow \mathbf{R}$ such that $x(t)+\beta x(t-r) \in C^{3}\left(\left[t_{x}, \infty\right), \mathbf{R}\right)$ and which satisfies equation (1.1) on $\left[t_{x}, \infty\right)$.

The asymptotic behavior of solutions in special cases $\beta=0$ or $r=0$ has been studied by serval authors see for example Ademola et al. [1, 2], Graef et al. [11, 12], Omeike [14], Oudjedi et al. [15], Remili et al. ([16][27]), Tunç [29, 30]. This problem for neutral differential equations has received considerable attention in recent years Baculíková [4], Mihalíková and Kostiková [5], Das and Misra [6], Dorociaková [7], Došlá and Liška [8, 9], Kulenovic et al. [13], Tian et al. [28], Li et al. [31], Yu et al. [32], Yu Jianshe [33]. Many books dealt with the neutral delay differential equation and obtained many good results, for example Arino et al. [3], El'sgol'ts[10].

Neutral differential equations have many applications. For example, these equations arise in the study of two or more simple oscillatory systems with some interconnections between them and in modeling physical problems such as vibration of masses attached to an elastic bar. In the qualitative analysis of such systems, the stability and asymptotic behavior of solutions play an important role.

However, as far as we know, there aren't works studying the asymptotic behavior of third order neutral differential equations with delay of the form 
(1.2) by using Lyapunov's functionals.

Motivated by this fact, in the present paper, we will investigate the asymptotic behavior, boundedness and square integrability of solutions of differential equation (1.2).

The organization of this article is as follows: In section 2, we give a theorem, which deal with asymptotic stability of every solution of the delay differential equation (1.1) when $h(t)=0$. In section 3, we introduced theorem which discuss the boundedness of the solutions of equation (1.2) for the case $h(t) \neq 0$. In section 4 , we introduced theorem which discuss the square integrability of the solutions of equation (1.2). Eventually, example is given in section 5 .

\section{Asymptotic stability}

We shall state here some assumptions which will be used on the functions that appeared in equation (1.1), and suppose that there are positive constants $a_{0}, a_{1}, c_{0}, b_{1}, L, \delta, d, \gamma, \eta$ and $M$ such that the following conditions are satisfied:

$\left.\mathrm{H}_{0}\right) 0<a_{0} \leq a(t) \leq a_{1}, \quad 0<c_{0} \leq c(t) \leq b(t) \leq b_{1}$; for all $t \geq t_{0}+r$,

$\left.\mathrm{H}_{1}\right) \delta\left(1+\frac{\beta}{2}\right)<d<a_{0}, \quad-L \leq b^{\prime}(t) \leq c^{\prime}(t) \leq 0$; for all $t \geq t_{0}+r$,

$\left.\mathrm{H}_{2}\right) \quad f(0)=0, \frac{f(x)}{x} \geq M>0(x \neq 0)$, and $f^{\prime}(x) \leq \delta$; for all $x$,

$\left.\mathrm{H}_{3}\right) \frac{1}{2} d a^{\prime}(t)-c_{0}\left(d-\left(1+\frac{\beta}{2}\right) \delta\right)+\frac{b_{1} \beta}{2}(1+\beta+\delta) \leq-\eta<0 ;$ for all $t \geq t_{0}+r$

$\left.\mathrm{H}_{4}\right) \beta\left(a_{1}-d\right)+b_{1} \beta(1+\beta)-(2-\beta)\left(a_{0}-d\right)=-\gamma<0$.

For the brevity, we put

$$
X(t)=x(t)+\beta x(t-r) .
$$

The equation (1.1) is equivalent to the following system

$$
\begin{aligned}
& x^{\prime}(t)=y(t) \\
& y^{\prime}(t)=z(t) \\
& Z^{\prime}(t)=-a(t) z(t)-b(t) y(t)-c(t) f(x(t))+c(t) \int_{t-r}^{t} f^{\prime}(x(s)) y(s) d s .
\end{aligned}
$$


According to the definition of $X(t)$ and (2), we have

$$
X^{\prime}(t)=y(t)+\beta y(t-r)=Y(t)
$$

and

$$
X^{\prime \prime}(t)=z(t)+\beta z(t-r)=Z(t) .
$$

Theorem 2.1. Assume that all assuptions $\left(H_{0}-H_{4}\right)$ hold. Then, every solution of (2) is asymptoticaly stable if

$$
r<\min \left\{\frac{2 \eta}{\delta(1+\beta+2 d)}, \frac{\gamma}{\delta(1+\beta)}\right\} .
$$

Proof. Define a Lyapunov functional $V(t, x, y, Z)$ as

$V=V_{0}+V_{1}+\mu \int_{t-r}^{t} z^{2}(s) d s+\sigma \int_{t-r}^{t} y^{2}(s) d s+\lambda \int_{-r}^{0} \int_{t+s}^{t} y^{2}(\tau) d \tau d s$,

where

$$
\begin{aligned}
V_{0} & =d c(t) F(x)+c(t) Y f(x)+\frac{b(t)}{2} Y^{2}, \\
V_{1} & =\frac{1}{2} Z^{2}+d y Z+\frac{1}{2} d a(t) y^{2},
\end{aligned}
$$

such that $F(x)=\int_{0}^{x} f(u) d u . \mu, \sigma$ and $\lambda$ are to be selected below suitably. First we shall show that $V(t)$ defined by $(2.2)$ is positive definite. From $H_{0}$ and $H_{1}$ we have

$$
\begin{aligned}
V_{1} & =\frac{1}{2}\left(Z^{2}+2 d y Z+d a(t) y^{2}\right) \\
& =\frac{1}{2}\left((Z+d y)^{2}+d y^{2}(a(t)-d)\right)
\end{aligned}
$$

In the same way, it follows that

$$
V_{1}=\frac{d a(t)}{2}\left(y+\frac{1}{a(t)} Z\right)^{2}+\frac{1}{2}\left(\frac{a(t)-d}{a(t)}\right) Z^{2} .
$$


Then

$$
\begin{aligned}
V_{1} & \left.=\frac{1}{4}(Z+d y)^{2}+\frac{1}{4} d a(t)\left(y+\frac{1}{a(t)} Z\right)^{2}+\frac{1}{4} d(a(t)-d) y^{2}+\frac{1}{4 a(t)}(a(t)-d)\right) Z^{2} \\
& \geq \frac{d\left(a_{0}-d\right)}{4} y^{2}+\frac{\left(a_{0}-d\right)}{4 a_{1}} Z^{2} .
\end{aligned}
$$

From this inequality we can deduce a positive constant $k_{0}$ such that

$$
V_{1} \geq k_{0}\left(y^{2}+Z^{2}\right)
$$

where $k_{0}=\min \left\{\frac{d}{4}\left(a_{0}-d\right), \frac{1}{4 a_{1}}\left(a_{0}-d\right)\right\}$. Using $H_{0}$, we obtain

$$
\begin{aligned}
V_{0} & =d c(t) F(x)+\frac{b(t)}{2}\left[Y^{2}+\frac{2 c(t) Y f(x)}{b(t)}\right] \\
& =d c(t) \int_{0}^{x} f(u) d u+\frac{b(t)}{2}\left[\left(Y+\frac{c(t)}{b(t)} f(x)\right)^{2}-\frac{c^{2}(t)}{b^{2}(t)} f^{2}(x)\right] \\
& \geq d c(t) \int_{0}^{x} f(u) d u-\frac{c^{2}(t)}{2 b(t)} f^{2}(x) .
\end{aligned}
$$

Since $f(0)=0$ and $f^{\prime}(x) \leq \delta$, it follows that

$$
\frac{1}{2} f^{2}(x)=\int_{0}^{x} f(u) f^{\prime}(u) d u \leq \delta \int_{0}^{x} f(u) d u .
$$

Thus, from $H_{1}$ we get

$$
\begin{aligned}
V_{0} & \geq d c(t) \int_{0}^{x}\left(1-\frac{\delta}{d}\right) f(u) d u \\
& \geq \delta_{1} \int_{0}^{x} f(u) d u=\delta_{1} F(x)
\end{aligned}
$$

where $\delta_{1}=d c_{0}\left(1-\frac{\delta}{d}\right)$. Observe that by $H_{2}$ we have

$$
\frac{f^{2}(x)}{x^{2}} \geq M^{2}
$$

which implies that

$$
F(x) \geq \frac{1}{2 \delta} f^{2}(x) \geq \frac{M^{2}}{2 \delta} x^{2}(t)
$$


Since

$$
\sigma \int_{t-r}^{t} y^{2}(s) d s+\mu \int_{t-r}^{t} z^{2}(s) d s+\lambda \int_{-r}^{0} \int_{t+s}^{t} y^{2}(\tau) d \tau d s>0
$$

it follows that

$$
V \geq k_{1}\left(Z^{2}+y^{2}+x^{2}\right)
$$

where $k_{1}=\min \left\{k_{0}, \frac{M^{2} \delta_{1}}{2 \delta}\right\}$. It is not difficult to verify that

$$
W(x, y, Z)=k_{1}\left(Z^{2}+y^{2}+x^{2}\right)=0 \Leftrightarrow x=y=Z=0
$$

and

$$
V \geq k_{1}\left(Z^{2}+y^{2}+x^{2}\right)=W(x, y, Z)>0 \text { if }(x, y, Z) \neq 0 .
$$

The derivative of the functional $\mathrm{V}$ along the trajectories of the system (2) is given by

$V_{(2)}^{\prime}$

$$
\begin{aligned}
& =d c^{\prime}(t) F(x)+c^{\prime}(t) Y f(x)+\frac{b^{\prime}(t)}{2} Y^{2}+\frac{1}{2} d a^{\prime}(t) y^{2}+\beta c(t) y y(t-r) f^{\prime}(x)+b(t) \beta y(t-r) z \\
& +b(t) \beta^{2} y(t-r) z(t-r)-\sigma y^{2}(t-r)-d b(t) y^{2}+c(t) y^{2} f^{\prime}(x)+\sigma y^{2}+\lambda r y^{2} \\
& +(d-a(t)) z^{2}+\mu z^{2}+\beta(d-a(t)) z z(t-r)-\mu z^{2}(t-r)-\lambda \int_{t-r}^{t} y^{2}(s) d s \\
& +c(t)(z+\beta z(t-r)+d y) \int_{t-r}^{t} f^{\prime}(x(s)) y(s) d s .
\end{aligned}
$$

We claim that

$$
d c^{\prime}(t) F(x)+c^{\prime}(t) Y f(x)+\frac{b^{\prime}(t)}{2} Y^{2} \leq 0,
$$

for all $t \geq 0, x$ and $y$. The remaining of this proof follows the strategy indicated in the proof of Theorem 3.1 in [22] and hence it is omitted.

By the condition $\mathrm{H}_{2}$ and applying the estimate $2 u v \leq u^{2}+v^{2}$ we obtain

$$
\begin{aligned}
z \int_{t-r}^{t} f^{\prime}(x(s)) y(s) d s & \leq \frac{\delta r}{2} z^{2}+\frac{\delta}{2} \int_{t-r}^{t} y^{2}(s) d s \\
\beta z(t-r) \int_{t-r}^{t} f^{\prime}(x(s)) y(s) d s & \leq \frac{\beta \delta r}{2} z^{2}(t-r)+\frac{\delta \beta}{2} \int_{t-r}^{t} y^{2}(s) d s, \\
d y \int_{t-r}^{t} f^{\prime}(x(s)) y(s) d s & \leq \frac{\delta r}{2} d y^{2}++\frac{\delta d}{2} \int_{t-r}^{t} y^{2}(s) d s .
\end{aligned}
$$

From conditions $\mathrm{H}_{0}$ and $\mathrm{H}_{1}$ and the above estimates it is easy to see that $V_{(2)}^{\prime}$ can be replaced by 


$$
\begin{aligned}
V_{(2)}^{\prime} & \leq\left(\frac{1}{2} d a^{\prime}(t)-b(t)\left(d-\delta\left(1+\frac{\beta}{2}\right) \frac{c(t)}{b(t)}\right)+\sigma+\frac{d \delta r}{2}+\lambda r\right) y^{2}(t) \\
& +\left(\mu-\frac{(2-\beta)\left(a_{0}-d\right)-\beta b_{1}}{2}+\frac{\delta r}{2}\right) z^{2}(t) \\
& +\left(\frac{b_{1} \beta}{2}(1+\beta)+\frac{\delta \beta b_{1}}{2}-\sigma\right) y^{2}(t-r) \\
& +\left(\frac{\beta\left(a_{1}-d\right)+b_{1} \beta^{2}}{2}-\mu+\beta \frac{\delta r}{2}\right) z^{2}(t-r) \\
& +\left(\frac{\delta}{2}+\beta \frac{\delta}{2}+\frac{d \delta}{2}-\lambda\right) \int_{t-r}^{t} y^{2}(s) d s
\end{aligned}
$$

Let

$\mu=\frac{\beta\left(a_{1}-d\right)+b_{1} \beta^{2}+\beta \delta r}{2}, \quad \lambda=\frac{\delta}{2}(1+\beta+d) \quad$ and $\quad \sigma=\frac{b_{1} \beta}{2}(1+\beta+\delta)$,

the last inequality becomes

$$
\begin{aligned}
V_{(2)}^{\prime} & \leq\left(\frac{1}{2} d a^{\prime}(t)-c_{0}\left(d-\left(1+\frac{\beta}{2}\right) \delta\right)+\frac{b_{1} \beta}{2}(1+\beta+\delta)+\frac{\delta r}{2}(1+\beta+2 d)\right) y^{2}(t) \\
& +\frac{1}{2}\left(\beta\left(a_{1}-d\right)+b_{1} \beta(1+\beta)-(2-\beta)\left(a_{0}-d\right)+\delta r(1+\beta)\right) z^{2}(t) \\
& \leq\left(-\eta+\frac{\delta r}{2}(1+\beta+2 d)\right) y^{2}(t)+\frac{1}{2}(-\gamma+\delta r(1+\beta)) z^{2}(t) .
\end{aligned}
$$

Therefore, from $H_{3}$ and $H_{4}$ there exists a positive constant $N$ such that

$$
V_{(2)}^{\prime} \leq-N\left(y^{2}(t)+z^{2}(t)\right)
$$

provided that

$$
r<\min \left\{\frac{2 \eta}{\delta(1+\beta+2 d)}, \frac{\gamma}{\delta(1+\beta)}\right\} .
$$

Finally, it follows that

$$
V_{(2)}^{\prime}(t, x, y, Z)=0 \quad \text { if and only if } \quad x=y=Z=0
$$

and

$$
V_{(2)}^{\prime}(t, x, y, Z)<0 \text { for }(x, y, Z) \neq 0
$$


Thus, all the conditions of theorem are satisfied. This shows that every solution of system (2) is asymptotically stable. The proof of Theorem 2.1 is now completed.

\section{Boundedness}

We would need to write (1.2) in the form

$$
\begin{aligned}
& x^{\prime}(t)=y(t) \\
& y^{\prime}(t)=z(t) \\
& Z^{\prime}(t)=-a(t) z(t)-b(t) y(t)-c(t) f(x(t))+h(t)+c(t) \int_{t-r}^{t} f^{\prime}(x(s)) y(s) d s,
\end{aligned}
$$

to study the boundedness of solutions of (3).

We conclude that

Our main theorem in this section is stated with respect to (3) as follows:

Theorem 3.1. Assume that all the conditions of Theorem 2.1 are satisfied and there exists a positive constant $D_{1}$ such that :

$\left.H_{5}\right) \int_{t_{1}}^{t}|h(s)| d s<D_{1}$.

Then there exists a positive constant $D$ such that any solution of (3) satisfies

$$
|x(t)| \leq D,|y(t)| \leq D,|Z(t)| \leq D
$$

Proof. On differentiating (2.2) along the system (3.1) we obtain

$$
V_{(3)}^{\prime}=V_{(2)}^{\prime}+h(t)(d y+Z)
$$

since $V_{(2)}^{\prime} \leq 0$, then it follows that

$$
V_{(3)}^{\prime} \leq K_{2}|h(t)|(|y|+|Z|)
$$

where $K_{2}=\max \{d, 1\}$. Since $|y| \leq y^{2}+1,|Z| \leq Z^{2}+1$ and the inequality (2.3), we obtain

$$
\begin{aligned}
V_{(3)}^{\prime} & \leq K_{2}|h(t)|\left(y^{2}+Z^{2}+2\right) \\
& \leq K_{3}|h(t)| V(t)+2 K_{2}|h(t)|
\end{aligned}
$$


where $K_{3}:=k_{1}^{-1} K_{2}>0$.

Integrating both sides (3.3) from $t_{1}$ to $t, t \geq t_{1}=t_{0}+r$, one can easily obtain

$$
V(t)-V\left(t_{1}\right) \leq 2 K_{2} \int_{t_{1}}^{t}|h(s)| d s+K_{3} \int_{t_{1}}^{t} V(s)|h(s)| d s .
$$

Thus

$$
V(t) \leq V\left(t_{1}\right)+2 K_{2} D_{1}+K_{3} \int_{t_{1}}^{t} V(s)|h(s)| d s .
$$

Using Gronwall inequality it follows that

$$
V(t) \leq\left(V\left(t_{1}\right)+2 K_{2} D_{1}\right) \exp \left(K_{3} \int_{t_{1}}^{t}|h(s)| d s\right) \leq D_{2}
$$

where $D_{2}=\left(V\left(t_{1}\right)+2 K_{2} D_{1}\right) \exp \left(K_{3} D_{1}\right)$.

This completes the proof of Theorem 3.1.

\section{Square Integrability}

Our next result concerns the square integrability of solutions of equation (1.2).

Theorem 4.1. In addition to the assumptions of Theorem 3.1, if we assume that

$\left.H_{6}\right) c_{0} M-\frac{b_{1}}{2}>0$

$\left.H_{7}\right) \int_{t_{1}}^{+\infty}\left|a^{\prime}(s)\right| d s<A$.

Then all the solutions of (1.2) and their derivatives are elements of $L^{2}\left[t_{1},+\infty\right)$.

Proof. Define W(t) as

$$
W(t)=V(t)+\varepsilon \int_{t_{1}}^{t}\left(z^{2}(s)+y^{2}(s)\right) d s, \quad \forall t \geq t_{1},
$$

where $\varepsilon>0$ is a constant to be specified later. By differentiating $\mathrm{W}(\mathrm{t})$ along the solution of system (3) and using (2.4) and (3.3) we obtain

$$
W_{(3)}^{\prime}(t) \leq(\varepsilon-N)\left(z(t)^{2}+y(t)^{2}\right)+\left(K_{3} V(t)+2 K_{2}\right)|h(t)| .
$$


If we choose $\varepsilon-N<0$, then from (3.4) we get

$$
W_{(3)}^{\prime}(t) \leq K_{4}|h(t)|,
$$

where $K_{4}=K_{3} D_{2}+2 K_{2}$. Integrating (4.2) from $t_{1}$ to $t$, and using condition $\left(H_{5}\right)$ of Theorem 3.1 we obtain

$$
W(t)-W\left(t_{1}\right)=\int_{t_{1}}^{t} W_{(3)}^{\prime}(s) d s \leq K_{4} D_{1}
$$

Using equality $V\left(t_{1}\right)=W\left(t_{1}\right)$ we get

$$
W(t) \leq K_{4} D_{1}+V\left(t_{1}\right)
$$

We can conclude by (4.1) that

$$
\int_{t_{1}}^{t}\left(y^{2}(s)+z^{2}(s)\right) d s<\frac{K_{4} D_{1}+V\left(t_{1}\right)}{\varepsilon},
$$

which imply the existence of positive constants $\sigma_{1}$ and $\sigma_{2}$ such that

$$
\int_{t_{1}}^{t} x^{\prime \prime 2}(s) d s=\int_{t_{1}}^{t} z^{2}(s) d s \leq \sigma_{2}
$$

and

$$
\int_{t_{1}}^{t} x^{\prime 2}(s) d s=\int_{t_{1}}^{t} y^{2}(s) d s \leq \sigma_{1} .
$$

We assert that $\int_{t_{1}}^{t} x^{2}(s) d s<\infty$, to prove this we multiply (1.2) by $x(t-r)$, we obtain

$x(t-r) x^{\prime \prime \prime}(t)+\beta x(t-r) x^{\prime \prime \prime}(t-r)+a(t) x(t-r) x^{\prime \prime}(t)+b(t) x(t-r) x^{\prime}(t)$

$$
+c(t) x(t-r) f(x(t-r))=x(t-r) h(t) .
$$

Integrating (??) from $t_{1}$ to $t$, we have

$$
\int_{t_{1}}^{t} c(s) x(s-r) f(x(s-r)) d s=\Delta_{1}(t)+\Delta_{2}(t)+\Delta_{3}(t),
$$

where 


$$
\begin{aligned}
& \Delta_{1}(t)=-\int_{t_{1}}^{t}\left(x(s-r) x^{\prime \prime \prime}(s)+\beta x(s-r) x^{\prime \prime \prime}(s-r)\right) d s \\
& \Delta_{2}(t)=-\int_{t_{1}}^{t}\left(a(s) x(s-r) x^{\prime \prime}(s)+b(s) x(s-r) x^{\prime}(s)\right) d s, \\
& \Delta_{3}(t)=\int_{t_{1}}^{t} h(s) x(s-r) d s .
\end{aligned}
$$

Integrating by parts and using the estimate $2 u v \leq u^{2}+v^{2}$ we obtain

$$
\begin{aligned}
\Delta_{1}(t) & =M_{1}(t)-M_{1}\left(t_{1}\right)+\int_{t_{1}}^{t} x^{\prime}(s-r) x^{\prime \prime}(s) d s \\
& \leq\left|M_{1}(t)-M_{1}\left(t_{1}\right)\right|+\int_{t_{1}}^{t} \frac{1}{2}\left(x^{\prime 2}(s-r)+x^{\prime 2}(s)\right) d s
\end{aligned}
$$

where

$$
M_{1}(t)=-x(t-r) X^{\prime \prime}(t)+\frac{\beta}{2} x^{2}(t-r) .
$$

By the fact that

$$
\int_{t_{1}}^{t} x^{\prime 2}(s-r) d s=\int_{t_{0}}^{t-r} x^{2}(u) d u \leq \int_{t_{0}}^{t_{1}} x^{\prime 2}(u) d u+\sigma_{1} \leq n+\sigma_{1} .
$$

We remark by our hypothesis and the inequalities (3.2) that $\left|M_{1}(t)-M_{1}\left(t_{1}\right)\right| \leq D^{2}\left(\frac{3 \beta}{2}+1\right)+\left|M_{1}\left(t_{1}\right)\right|$, for all $t \geq t_{1}$.

Thus

$$
\Delta_{1}(t) \leq D^{2}\left(\frac{3 \beta}{2}+1\right)+\left|M_{1}\left(t_{1}\right)\right|+\frac{1}{2}\left(n+\sigma_{1}+\sigma_{2}\right)=l_{1} .
$$

Similarly we have

$$
\begin{aligned}
\Delta_{2}(t)= & -\int_{t_{1}}^{t}\left(a(s) x(s-r) x^{\prime \prime}(s)+b(s) x(s-r) x^{\prime}(s)\right) d s \\
= & -a(t) x(t-r) x^{\prime}(t)+a(t) \int_{t_{1}}^{t} x^{\prime}(s) x^{\prime}(s-r) d s+\int_{t_{1}}^{t} a^{\prime}(s) x(s-r) x^{\prime}(s) d s \\
& -\int_{t_{1}}^{t} a^{\prime}(s)\left[\int_{t_{1}}^{s} x^{\prime}(u) x^{\prime}(u-r) d u\right] d s-\int_{t_{1}}^{t} b(s) x(s-r) x^{\prime}(s) d s+M_{2}\left(t_{1}\right)
\end{aligned}
$$


where $M_{2}\left(t_{1}\right)=a\left(t_{1}\right) x\left(t_{1}-r\right) x^{\prime}\left(t_{1}\right)$. Then, from condition $H_{7}$ we have

$$
\begin{aligned}
& \quad \Delta_{2}(t) \leq a_{1}\left(D^{2}+\sigma_{1}+\frac{n}{2}\right)+ \\
& \int_{t_{1}}^{t}\left(\left|a^{\prime}(s)\right|\left|x^{\prime}(s)\right||x(s-r)|+\left|a^{\prime}(s)\right|\left[\int_{t_{1}}^{s} x^{\prime}(u) x^{\prime}(u-r) d u\right]\right) d s \\
& +\frac{b_{1}}{2} \int_{t_{1}}^{t} x^{2}(s-r) d s+\frac{b_{1}}{2} \int_{t_{1}}^{t} x^{\prime 2}(s) d s+\left|M_{2}\left(t_{1}\right)\right| \\
& \leq a_{1}\left(D^{2}+\sigma_{1}+\frac{n}{2}\right)+\left|M_{2}\left(t_{1}\right)\right|+\left(D^{2}+\sigma_{1}+\frac{n}{2}\right) \int_{t_{1}}^{t}\left|a^{\prime}(s)\right| d s \\
& +\frac{b_{1}}{2} \int_{t_{1}}^{t} x^{2}(s-r) d s+\frac{b_{1}}{2} \sigma_{1} \\
& \leq a_{1}\left(D^{2}+\sigma_{1}+\frac{n}{2}\right)+\left|M_{2}\left(t_{1}\right)\right|+\left(D^{2}+\sigma_{1}+\frac{n}{2}\right) A+\frac{b_{1}}{2} \sigma_{1} \\
& +\frac{b_{1}}{2} \int_{t_{1}}^{t} x^{2}(s-r) d s .
\end{aligned}
$$

Next

$$
\begin{aligned}
\Delta_{3}(t) & \leq \int_{t_{1}}^{t}|x(s-r)||h(s)| d s \\
& \leq D \int_{t_{1}}^{t} h(s) d s \\
& \leq D_{1} D .
\end{aligned}
$$

By (4.4) and condition $\left(H_{6}\right)$ of Theorem 4.1 we obtain

$$
c_{0} M \int_{t_{1}}^{t} x^{2}(s-r) d s \leq \int_{t_{1}}^{t} c(s) x(s-r) f(x(s-r)) d s \leq K+\frac{b_{1}}{2} \int_{t_{1}}^{t} x^{2}(s-r) d s,
$$

then

$$
\left(c_{0} M-\frac{b_{1}}{2}\right) \int_{t_{1}}^{t} x^{2}(s-r) d s \leq K
$$

where

$$
K=l_{1}+\left(a_{1}+A\right)\left(D^{2}+\sigma_{1}+\frac{n}{2}\right)+\left|M_{2}\left(t_{1}\right)\right|+\frac{b_{1}}{2} \sigma_{1}+D_{1} D .
$$

from which it follows that $\int_{t_{1}}^{t} x^{2}(s-r) d s<\infty$ hence $\int_{t_{1}}^{+\infty} x^{2}(s) d s<\infty$. This fact completes the proof of theorem.

\section{Example}

We consider the following third order non-autonomous delay neutral differential equation 


$$
\begin{aligned}
& {[x(t)+\beta x(t-r)]^{\prime \prime \prime}+\left(\frac{1}{\pi} \arctan t+\frac{13}{2}\right) x^{\prime \prime}+\left(\frac{1}{2+t^{2}}+1\right) x^{\prime}} \\
& +\left(\frac{1}{4+t^{2}}+1\right)\left(x(t-r)+\frac{x(t-r)}{1+x^{2}(t-r)}\right)=\frac{\sin t}{1+t^{2}} .
\end{aligned}
$$

Now, it is easy to see that for all $t \geq t_{1}$,

$$
\begin{aligned}
& 6=a_{0} \leq a(t)=\frac{1}{\pi} \arctan t+\frac{13}{2} \leq 7=a_{1}, \quad a^{\prime}(t)=\frac{1}{\pi\left(1+t^{2}\right)} \leq \frac{1}{\pi}, \\
& 1=c_{0} \leq c(t)=\frac{1}{4+t^{2}}+1 \leq b(t)=\frac{1}{2+t^{2}}+1 \leq \frac{3}{2}=b_{1}, \\
& 1=M \leq \frac{f(x)}{x}=1+\frac{1}{1+x^{2}} \text { with } x \neq 0, \text { and }\left|f^{\prime}(x)\right| \leq 2=\delta, \\
& \delta\left(1+\frac{\beta}{2}\right)=\frac{9}{4}<d<6=a_{0}, \text { for } \beta=\frac{1}{4}, \\
& c_{0} M-\frac{b_{1}}{2}=1-\frac{3}{4}>0, \\
& \frac{1}{2} d a^{\prime}(t)-c_{0}\left(d-\left(1+\frac{\beta}{2}\right) \delta\right)+\frac{b_{1} \beta}{2}(1+\beta+\delta) \leq-\frac{1}{2}<0, \text { for } d=4, \\
& \beta\left(a_{1}-d\right)-(2-\beta)\left(a_{0}-d\right)+\beta b_{1}(1+\beta)=-2,28<0, \\
& \int_{t_{1}}^{+\infty}\left|a^{\prime}(s)\right| d s=\frac{1}{\pi} \int_{t_{1}}^{+\infty} \frac{1}{1+s^{2}}<+\infty, \\
& \int_{t_{1}}^{+\infty}|h(s)| d s \leq \int_{t_{1}}^{+\infty} \frac{1}{1+s^{2}}<+\infty .
\end{aligned}
$$

All the assumptions of Theorem 4.1 are satisfied, we can conclude that every solution of (5.1) and their derivatives are bounded and elements of $L^{2}\left[t_{1},+\infty\right)$

\section{References}

[1] A. T. Ademola, and P.O.Arawomo, Uniform stability and boundedness of solutions of nonlinear delay differential equations of third order. Math. J. Okayama Univ. 55, pp. 157-166, (2013). 
[2] A. T. Ademola, and O. M. Arawomo, Ogunlaran and E. A. Oyekan, Uniform stability, boundedness and asymptotic behaviour of solutions of some third order nonlinear delay differential equations. Differential Equations and Control Processes, Issue 4, pp. 43-66, (2013).

[3] O. Arino, M. L. Hbid, and E. Ait Dads, Delay differential equations and applications. NATO sciences series. Berlin, Springer, (2006).

[4] B. Baculíková, J. Džurina, On the asymptotic behavior of a class of third order nonlinear neutral differential equations, Cent. Eur. J. Math., 8, pp. 1091-1103, (2010).

[5] B. Mihalíková and E. Kostiková, Boundedness and oscillation of third order neutral differential equations. Tatra Mt. Math. Publ. 43, pp. 137-144, (2009).

[6] P. Das and N. Misra, A necessary and sufficient condition for the solution of a functional differential equation to be oscillatory or tend to zero, J. Math. Anal. Appl. 204, pp. 78-87, (1997).

[7] B. Dorociaková, Some nonoscillatory properties of third order differential equations of neutral type. Tatra Mt. Math. Publ. 38, pp. 71-76, (2007).

[8] Z. Došlá, P. Liška, Oscillation of third-order nonlinear neutral differential equations. Appl. Math. Lett., 56, pp. 42-48, (2016).

[9] Z. Došla, P. Liška, Comparison theorems for third order neutral differential equations. Electronic Journal of Differential Equations, Vol. 38 , pp. 1-13, (2016).

[10] L. E. El'sgol'ts, Introduction to the theory of differential equations with deviating arguments. Translated from the Russian by Robert J. McLaughlin Holden-Day, Inc., San Francisco, Calif.-LondonAmsterdam (1966).

[11] J. R. Graef, D. Beldjerd and M. Remili, On stability, ultimate boundedness, and existence of periodic solutions of certain third order differential equations with delay. PanAmerican Mathematical Journal 25, pp. 82-94, (2015).

[12] J. R. Graef, L. D. Oudjedi and M. Remili Stability and square integrability of solutions of nonlinear third order differential equations. 
Dynamics of Continuous, Discrete and Impulsive Systems Series A: Mathematical Analysis 22, pp. 313-324, (2015).

[13] M. R. S. Kulenovic, G. Ladas, A. Meimaridou, Stability of solutions of linear delay differential equations. Proc. Amer. Math. Soc., 100, pp. 433-441, (1987).

[14] M. O. Omeike, New results on the stability of solution of some nonautonomous delay differential equations of the third order. Differential Equations and Control Processes 2010 1, pp. 18-29, (2010).

[15] L. D. Oudjedi, D. Beldjerd, and M. Remili, On the Stability of Solutions for non- autonomous delay differential equations of third-order, Differential Equations and Control Processes 1, pp. 22-34, (2014).

[16] M. Remili, D. Beldjerd, A boundedness and stability results for a kind of third order delay differential equations. Applications and Applied Mathematics, vol. 10, Issue 2, pp. 772-782, (2015).

[17] M. Remili, and D. Beldjerd, On the asymptotic behavior of the solutions of third order delay differential equations. Rend. Circ. Mat. Palermo 63, pp. 447-455, (2014).

[18] M. Remili, D. Beldjerd, On ultimate boundedness and existence of periodic solutions of kind of third order delay differential equations. Acta Universitatis Matthiae Belii, series Mathematics Issue, pp. 1-15, (2016).

[19] M. Remili, D. Beldjerd, Stability and ultimate boundedness of solutions of some third order differential equations with delay. Journal of the Association of Arab Universities for Basic and Applied Sciences 23, pp. 90-95, (2017).

[20] M. Remili, and L. D. Oudjedi, Boundedness and stability in third order nonlinear differential equations with bounded delay. Analele Universităţii Oradea Fasc. Matematica, Tom XXIII, Issue No. 1, pp. 135-143, (2016).

[21] M. Remili, and L. D. Oudjedi, Boundedness and stability in third order nonlinear differential equations with multiple deviating arguments. Archivum Mathematicum, Vol. 52, No. 2, pp. 79-90, (2016). 
[22] M. Remili, and L. D. Oudjedi, Stability and boundedness of the solutions of non autonomous third order differential equations with delay. Acta Univ. Palacki. Olomuc., Fac. rer. nat., Mathematica 53, 2, pp. 139-147, (2014).

[23] M. Remili, and L. D. Oudjedi, Stability of the solutions of nonlinear third order differential equations with multiple deviating arguments. Acta Univ. Sapientiae, Mathematica, 8, 1, pp. 150-165, (2016).

[24] M. Remili, and L. D. Oudjedi, On asymptotic stability of solutions to third order nonlinear delay differential equation. Filomat, 30, 12, pp. 3217-3226, (2016).

[25] M. Remili, L. D. Oudjedi, and Beldjerd, D., On the qualitative behaviors of solutions to a kind of nonlinear third order differential equation with delay. Communications in Applied Analysis 20, pp. 53-64, (2016).

[26] M. Remili, and L. D. Oudjedi, Uniform stability and boundedness of a kind of third order delay differential equations, Bull. Comput. Appl. Math., Vol. 2, No.1, pp. 25-35, (2014).

[27] M. Remili, and L. D. Oudjedi, Uniform ultimate boundedness and asymptotic behaviour of third order nonlinear delay differential equation. Afrika Matematika, Vol. 27, Issue 7, pp. 1227-1237, (2016).

[28] Y.-Z. Tian, Y.-L. Cai, Y.-L. Fu, T.-X. Li, Oscillation and asymptotic behavior of third-order neutral differential equations with distributed deviating arguments. Adv. Difference Equ., 267, 14 pages, (2015).

[29] C. Tunç, On the stability and boundedness of solutions to third order nonlinear differential equations with retarded argument. Nonlinear Dynam. 57, No. 1-2, pp. 97-106, (2009).

[30] C. Tunç, Some stability and boundedness conditions for nonautonomous differential equations with deviating arguments, E. J. Qualitative Theory of Diff. Equ., No. 1., pp. 1-12, (2010).

[31] T.-X. Li, C.-H. Zhang, G.-J. Xing, Oscillation of third-order neutral delay differential equations. Abstr. Appl. Anal., 11 pages, (2012).

[32] J. Yu, Z. Wang, C. Qian, Oscillation of neutral delay differential equation. Bull. Austral. Math. Soc. 45, pp. 195-200, (1992). 
[33] Yu Jianshe, Asymptotic stability for a class of nonautonomous neutral differential equations. Chin. Ann. of Math, 18 B (4), pp. 449-456, (1997).

\section{Linda. D. Oudjedi}

Department of Mathematics, University of Oran 1 Ahmed Ben Bella, 31000 Oran,

Algeria

e-mail : oudjedi@yahoo.fr

\section{Belaib Lekhmissi}

Department of Mathematics, University of Oran 1 Ahmed Ben Bella, 31000 Oran,

Algeria

e-mail : belaib-lekhmissi@yahoo.fr

and

\section{Moussadek Remili}

Department of Mathematics, University of Oran 1 Ahmed Ben Bella, 31000 Oran,

Algeria

e-mail : remilimous@gmail.com 